strongly dependent on the method used. We focused on gaseous emboli since we believe that formation of gaseous emboli is indeed caused by factors inherent in extracorporeal circulation, whereas particulate emboli are mainly derived from manipulation of the heart and the aorta. By choosing a detection window without aortic manipulation, we were able to obtain more gaseous than particulate emboli counts. The number of gaseous counts differed significantly between the two methods, whereas the particulate counts did not. Coming back to your point that air may enter the circuit via the venous purse string, we always observed a distinct filling of the right heart and atrium, meaning that there is a greater chance to have blood leakage than air entrapment. In our opinion, an active air removal in this setting is completely unnecessary.
Dr Aldea. This is a very important development in general using these technologies, but since most of the procedures that we do now are open cardiac procedures, how would you translate some of these advances to intracardiac procedures?

Dr Khosravi. There is a study from Remadi's group in France which used the MECC for aortic valve replacement. Our own experience in open cases is rather limited and not so enthusiastic. First, you must ensure that there is no atrial septal defect or use a double venous cannulation. Second, you are facing quite a large amount of intracardiac suction blood and you must have a concept of intraoperative blood processing. Thus, you give up part of your MECC principles. Therefore, we now restrict the use of the MECC system to CABG cases.

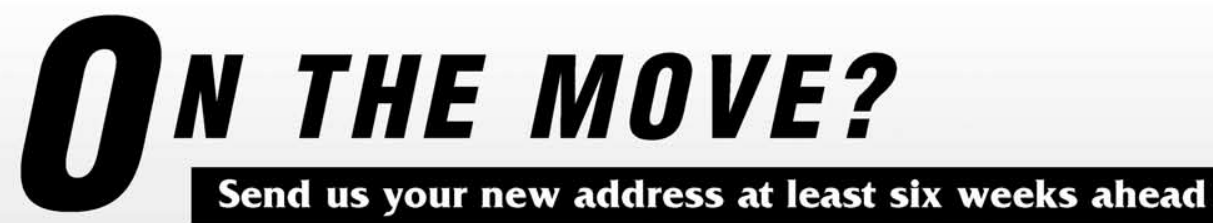

Don't miss a single issue of the journal! To ensure prompt service when you change your address, please photocopy and complete the form below.

Please send your change of address notification at least six weeks before your move to ensure continued service. We regret we cannot guarantee replacement of issues missed due to late notification.

\section{JOURNAL TITLE:}

Fill in the title of the journal here.

\section{OLD ADDRESS:}

Affix the address label from a recent issue of the journal here.

\section{NEW ADDRESS:}

Clearly print your new address here.

Name

Address

City/State/ZIP
COPY AND MAIL THIS FORM TO:

Elsevier Inc.

Subscription Customer Service

6277 Sea Harbor Dr

Orlando, FL 32887
OR FAX TO:

407-363-9661

OR E-mail:

elspcs@elsevier.com
OR PHONE:

800-654-2452

Outside the U.S., call

407-345-4000 